\title{
Effect of Diacetyl Monoxime Thiosemicarbazone on the Corrosion of Aged 18 Ni 250 Grade Maraging Steel in Sulphuric Acid Solution
}

\author{
T. Poornima, ${ }^{1}$ Jagannath Nayak, ${ }^{2}$ and A. Nityananda Shetty ${ }^{3}$ \\ ${ }^{1}$ Department of Science and Humanities, PESIT, Bangalore 560085, India \\ ${ }^{2}$ Department of Metallurgical and Materials Engineering, National Institute of Technology Karnataka, Surathkal, \\ Srinivasnagar, Karnataka 75025, India \\ ${ }^{3}$ Department of Chemistry, National Institute of Technology Karnataka, Surathkal, Srinivasnagar, Karnataka 575025, India
}

Correspondence should be addressed to A. Nityananda Shetty, nityashreya@gmail.com

Received 31 July 2012; Accepted 6 November 2012

Academic Editor: Sunghak Lee

Copyright (๑) 2012 T. Poornima et al. This is an open access article distributed under the Creative Commons Attribution License, which permits unrestricted use, distribution, and reproduction in any medium, provided the original work is properly cited.

The corrosion inhibition of the aged $18 \mathrm{Ni} 250$ grade maraging steel in $0.5 \mathrm{M}$ sulphuric acid by diacetyl monoxime thiosemicarbazone (DAMTSC) at 303-323 K has been investigated by potentiodynamic polarization, EIS, and SEM techniques. Good inhibition efficiency of DAMTSC was revealed even at low concentrations, which increased with the increase in DAMTSC concentration and decreased with the increase in temperature. The activation energies, $E_{a}$, as well as other thermodynamic parameters $\left(\Delta G_{\mathrm{ads}}^{0} ; \Delta H_{\mathrm{ads}}^{0} ; \Delta G_{\mathrm{ads}}^{0}\right)$, were evaluated and discussed. The adsorption of DAMTSC on the aged maraging steel surface was found to obey the Langmuir adsorption isotherm model and shows mixed type inhibition behavior.

\section{Introduction}

Corrosion of structural elements is a major issue for any industry because of the chemical environment of chemical processing. Maraging steels are special class of ultrahigh strength steels that differ from conventional steels in that they are hardened by a metallurgical reaction that does not involve carbon [1]. They derive high strength from age hardening of low carbon, Fe-Ni martensitic matrix [2]. The need for highly reliable substances of high strength and high ductility is gradually increasing with the development of aerospace industry. According to available literature, atmospheric exposure of $18 \mathrm{Ni}$ maraging steel leads to corrosion in a uniform manner and the steel becomes completely rust covered [3]. Pit depths tend to be shallower than high strength steels [4]. Critical and passive current densities increase as the structure is varied from fully annealed to fully aged [5]. Maraging steels are found to be less susceptible to hydrogen embrittlement than common high strength steels owing to significantly low diffusion of hydrogen in them [6]. Several technical papers covering alloy design, material processing, thermo-mechanical treatments, welding, strengthening mechanisms, and so forth, have been published [7]. Search in the literature reveals very little work being reported on the corrosion behavior and on the use of inhibitors in controlling corrosion of maraging steel except some of our publications $[8,9]$. Metals and alloys frequently come in contact with acid solutions during cleaning, pickling, descaling, acidising, and so forth. Materials used in acid environment should have good corrosion resistance. The present work is intended to study the corrosion inhibition of aged $18 \mathrm{Ni} 250$ grade maraging steel in $0.5 \mathrm{M}$ sulphuric acid medium using DAMTSC as inhibitor.

The majority of the well known inhibitors are organic compounds containing heteroatom, such as $\mathrm{O}, \mathrm{N}$, or $\mathrm{S}$ and multiple bonds or aromatic rings, which allow an adsorption on the metal surface through lone pair of electrons and/or pi electrons present in these molecules $[10,11]$. Sulphur containing compounds are preferred for $\mathrm{H}_{2} \mathrm{SO}_{4}$ while those containing nitrogen act more effectively in $\mathrm{HCl}$ [12]. The inhibition efficiency should increase in the order $\mathrm{O}<\mathrm{N}<$ $\mathrm{S}<\mathrm{P}$ [13]. The molecules that contain both nitrogen and 
TABLE 1: Composition of the aged maraging steel specimen.

\begin{tabular}{lc}
\hline Element & Composition \\
\hline $\mathrm{C}$ & $0.015 \%$ \\
$\mathrm{Ni}$ & $17-19 \%$ \\
$\mathrm{Mo}$ & $4.6-5.2 \%$ \\
$\mathrm{Co}$ & $7-8.5 \%$ \\
$\mathrm{Si}$ & $0.1 \%$ \\
$\mathrm{O}$ & $30 \mathrm{ppm}$ \\
$\mathrm{H}$ & $2.0 \mathrm{ppm}$ \\
$\mathrm{Ti}$ & $0.3-0.6 \%$ \\
$\mathrm{Al}$ & $0.005-0.15 \%$ \\
$\mathrm{Mn}$ & $0.1 \%$ \\
$\mathrm{P}$ & $0.01 \%$ \\
$\mathrm{~S}$ & $0.01 \%$ \\
$\mathrm{~N}$ & $30 \mathrm{ppm}$ \\
$\mathrm{Fe}$ & Balance \\
\hline
\end{tabular}

sulphur in their structures are of particular importance, since these provide an excellent inhibition compared with the compounds that contain only sulphur or nitrogen [14]. Thiosemicarbazones and their derivatives have continued to be subject of extensive investigation in chemistry and biology owing to their broad spectrum of antitumor [15], antimalarial [16], antiviral [17], antibacterial [18], antifungal [19], and many other applications including corrosion inhibition of metals [20-23].

\section{Experimental Methods}

2.1. Materials. The maraging steel samples (M 250 grade) in aged condition were taken from plates. The solution annealed and air cooled plates were subjected to aging treatment at $480 \pm 5^{\circ} \mathrm{C}$ for 3 hours and air cooled. Percentage composition of $18 \mathrm{Ni} 250$ grade aged maraging steel samples is given in Table 1. Cylindrical test coupons were cut from the plate and sealed with epoxy resin in such a way that, the area exposed to the medium is $0.503 \mathrm{~cm}^{2}$. These coupons were polished as per standard metallographic practice, belt grinding followed by polishing on emery papers, finally on polishing wheel using legated alumina to obtain mirror finish, degreased with acetone, washed with double distilled water, and dried before immersing in the corrosion medium. The inhibitor diacetyl monoxime thiosemicarbazone (DAMTSC) was synthesized as per the reported procedure [24] by reaction between diacetyl monoxime and thiosemicarbazide and its structure is given in Scheme 1.

2.2. Medium. Standard $0.5 \mathrm{M}$ sulphuric acid solution was prepared by diluting analar grade $98 \%$ sulphuric acid by using double distilled water. The solutions of inhibitor with $1.14 \times 10^{-4} \mathrm{M}, 2.85 \times 10^{-4} \mathrm{M}, 5.70 \times 10^{-4} \mathrm{M}$ and $8.55 \times 10^{-4} \mathrm{M}$ concentration were prepared in standard $0.5 \mathrm{M}$ sulphuric acid. Experiments were carried out using calibrated thermostat at temperatures $303 \mathrm{~K}, 308 \mathrm{~K}, 313 \mathrm{~K}$, $318 \mathrm{~K}, 323 \mathrm{~K}( \pm 0.5 \mathrm{~K})$.

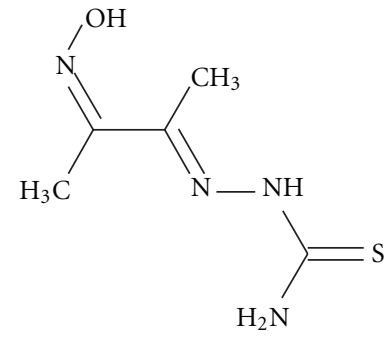

Scheme 1

\subsection{Electrochemical Measurement}

2.3.1. Tafel Polarisation Studies. Electrochemical measurements were carried out by using an electrochemical work station, Auto Lab 30 and GPES software. Tafel plot measurements were carried out using conventional three electrode Pyrex glass cell with platinum counter electrode and saturated calomel electrode (SCE) as reference electrode. All the values of potential are referred to the SCE. Finely polished maraging steel specimens were exposed to corrosion medium of sulphuric acid in the presence and absence of inhibitor at different temperatures and allowed to establish a steady state open circuit potential. The potentiodynamic currentpotential curves were recorded by polarizing the specimen to $-250 \mathrm{mV}$ cathodically and $+250 \mathrm{mV}$ anodically with respect to open circuit potential (OCP) at scan rate of $1 \mathrm{mV} \mathrm{s}^{-1}$.

2.3.2. Electrochemical Impedance Spectroscopy Studies (EIS). The corrosion behavior of the maraging steel specimen was also obtained from EIS technique using electrochemical work station, Auto Lab 30, and FRA software. In EIS technique a small amplitude ac signal of $10 \mathrm{mV}$ and frequency spectrum from $100 \mathrm{kHz}$ to $0.01 \mathrm{~Hz}$ was impressed at the OCP and impedance data were analyzed using Nyquist plots. The charge transfer resistance, $R_{\mathrm{ct}}$ was extracted from the diameter of the semicircle in Nyquist plot.

In all the above measurements, at least three similar results were considered and their average values are reported.

2.3.3. Scanning Electron Microscopy (SEM) Analysis. The SEM images were recorded using JEOL JSM-6380 LA analytical scanning electron microscope.

\section{Results and Discussion}

3.1. Tafel Polarization Measurement. The corrosion inhibition of aged maraging steel investigated in $0.5 \mathrm{M}$ sulphuric acid containing various concentration of DAMTSC inhibitor at different temperatures using Tafel polarization technique and Tafel plots at $303 \mathrm{~K}$ are shown in Figure 1. The valuable potentiodynamic polarization parameters including corrosion potential $\left(E_{\text {corr }}\right)$, corrosion current density $\left(I_{\text {corr }}\right)$, anodic and cathodic slopes $\left(b_{a}\right.$ and $\left.b_{c}\right)$, and corrosion rate 
(C.R) were calculated from Tafel plots and are summarized in Table 2. The C.R is calculated using

$$
\text { corrosion rate }(\mathrm{mm} / \mathrm{y})=\frac{3270(\mathrm{E} \cdot \mathrm{W}) I_{\mathrm{corr}}}{D}
$$

where 3270 is a constant that defines the unit of corrosion rate, $I_{\text {corr }}=$ corrosion current density in $\mathrm{A} / \mathrm{cm}^{2}, D=$ density of the corroding material, $8.23 \mathrm{~g} / \mathrm{cm}^{3}$, E.W = equivalent weight of corroding material (atomic weight/oxidation number), 29.2 [25]. The percentage inhibition efficiency (IE\%) was calculated from

$$
\mathrm{IE} \%=\frac{I_{\text {corr }}-I_{\text {corr (inh) }}}{I_{\text {corr }}} \times 100,
$$

where $I_{\text {corr }}$ and $I_{\text {corr (inh) }}$ are corrosion current densities in the absence and in the presence of inhibitor, respectively. The value of corrosion current density $\left(I_{\text {corr }}\right)$ decreased effectively even with low concentration of DAMTSC and inhibition efficiency increases with increase inhibitor concentration. The presence of inhibitor does not shift the $E_{\text {corr }}$ remarkably, implying that DAMTSC acts as mixed type inhibitor affecting both anodic and cathodic reactions [23]. According to Li and others [26], if the displacement in corrosion potential is more than $\pm 85 \mathrm{mV}$ with respect to corrosion potential of the blank, the inhibitor can be considered as a cathodic or anodic type. But the maximum displacement in this study is less than $10 \mathrm{mV}$, which indicates that DAMTSC is a mixed type inhibitor. According to Cao [27] if the shift in $E_{\text {corr }}$ is negligible the inhibition is most probably caused by a geometric blocking effect of the adsorbed inhibitive species on the surface of corroding metal. The anodic and cathodic Tafel slopes remain almost unchanged upon addition of inhibitor. Thus the adsorbed inhibitor acts by simple blocking of active sites for anodic and cathodic processes, thereby reducing the surface area for corrosion without affecting the corrosion mechanism $[28,29]$. The parallel cathodic Tafel curves suggest that the hydrogen evolution is activation controlled and the reduction mechanism is not affected by the presence of the inhibitors [30].

For anodic polarization curves of specimen with DAMTSC (in Figure 2), it seems that at the working electrode potential, higher than $-200 \mathrm{mV} / \mathrm{SCE}$, the presence of inhibitor does not change the current versus potential characteristics. At this potential, the anodic current increases steeply and a flat region is observed. This potential can be defined as desorption potential [31]. The phenomenon may be due to the obvious metal dissolution, which leads to desorption of the inhibitor molecule from the electrode surface. In this case, the desorption rate of the inhibitor is higher than its adsorption rate, so the corrosion current increases more obviously with rising potential [32]. At still higher polarization potential the anodic current density change drastically, resulting in sharp increase in Tafel slope. The Tafel slope of the third portion is nearly equal to that in the absence of DAMTSC. Above desorption potential coverage of inhibitor decreases rapidly. Similar conclusion was reported by Qu et al. [33].

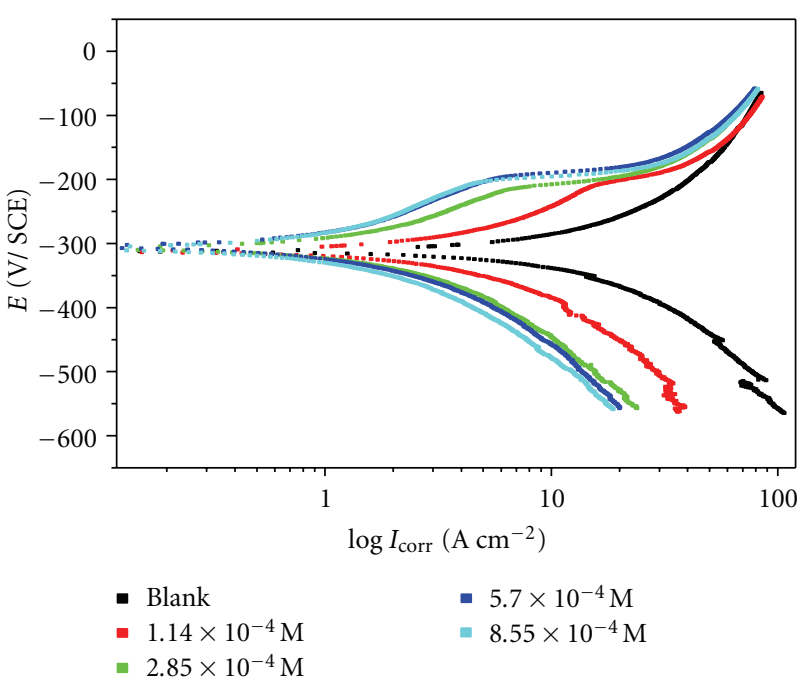

FIGURE 1: Tafel polarization curves for the aged maraging steel in $0.5 \mathrm{M}$ sulphuric acid containing different concentrations inhibitor.

3.2. Electrochemical Impedance Spectroscopy. The results of potentiodynamic polarization experiments were compared with the results of impedance measurements, since EIS has emerged as probably the most powerful technique currently available for identifying corrosion reaction mechanisms. In order to get more information about the corrosion inhibition of aged maraging steel specimens in $0.5 \mathrm{M}$ sulphuric acid containing different concentrations of DAMTSC, EIS measurements were carried out at different temperatures and they are displayed as Nyquists plots. The Nyquist plots obtained for aged samples of maraging steel specimens in $0.5 \mathrm{M}$ sulphuric acid with and without various concentrations of DAMTSC are as shown in Figure 2.

It is clear from the figures that the shapes of the impedance plots for inhibited specimen are different from those of uninhibited one. The Nyquists plots of aged maraging steel in $0.5 \mathrm{M} \mathrm{H}_{2} \mathrm{SO}_{4}$ without inhibitor are characterized by two time constants with a depressed capacitive semicircle at high frequency region (HF) followed by an inductive loop at low frequency (LF) region. These are not perfect semicircles, because the Nyquist plots obtained in the real system represent a general behavior where the double layer at the metal solution interface does not behave as an ideal capacitor [34]. The depressed capacitive loop with its centre below the real axis often refers to the frequency dispersion of interfacial impedance which has been attributed to the roughness, inhomogeneity of the solid surfaces, and adsorption of inhibitors [10]. The HF capacitive loop was attributed to charge transfer of the corrosion process and time constant of the electric double layer [35]. The LF inductive loop can be attributed to relaxation process obtained by adsorbed sulphate ions and protons [36]. It may also be attributed to the redissolution of the passivated surface at low frequencies [37]. In the present case, the low frequency inductive loop in inhibitor free acid medium can be attributed to surface dissolution process at low frequencies. Based on the shape 
TABLE 2: Results of Tafel polarization studies on aged maraging steel in $0.5 \mathrm{M}$ sulphuric acid with and without different concentrations of DAMTSC at various temperatures.

\begin{tabular}{|c|c|c|c|c|c|c|c|}
\hline Temp (K) & $\begin{array}{c}\text { Conc. of } \\
\text { inhibitor } \\
\left(\times 10^{-4}\right)(\mathrm{M})\end{array}$ & $E_{\text {corr }}(\mathrm{V})$ & $\begin{array}{c}I_{\text {corr }} \times\left(10^{-4}\right) \\
\left(\mathrm{A} \mathrm{cm}^{-2}\right)\end{array}$ & $b_{c}\left(\mathrm{~V} \mathrm{dec}^{-1}\right)$ & $b_{a}\left(\mathrm{~V} \mathrm{dec}^{-1}\right)$ & $\begin{array}{l}\text { C.R in } \\
\mathrm{mm} \mathrm{Y}^{-1}\end{array}$ & IE $(\%)$ \\
\hline \multirow[t]{5}{*}{303} & 0.00 & -0.310 & 75.26 & 0.107 & 0.103 & 87.30 & \\
\hline & 1.14 & -0.310 & 27.18 & 0.103 & 0.102 & 31.53 & 63.9 \\
\hline & 2.85 & -0.306 & 11.72 & 0.095 & 0.106 & 13.60 & 84.4 \\
\hline & 5.70 & -0.306 & 9.57 & 0.106 & 0.113 & 11.10 & 87.3 \\
\hline & 8.55 & -0.303 & 7.73 & 0.093 & 0.111 & 8.97 & 89.7 \\
\hline \multirow[t]{5}{*}{308} & 0.00 & -0.312 & 85.43 & 0.122 & 0.127 & 99.10 & \\
\hline & 1.14 & -0.310 & 32.07 & 0.127 & 0.098 & 37.20 & 62.5 \\
\hline & 2.85 & -0.309 & 21.64 & 0.098 & 0.112 & 25.10 & 74.7 \\
\hline & 5.70 & -0.304 & 13.19 & 0.112 & 0.115 & 15.30 & 84.6 \\
\hline & 8.55 & -0.307 & 10.99 & 0.115 & 0.118 & 12.75 & 87.1 \\
\hline \multirow[t]{5}{*}{313} & 0.00 & -0.309 & 96.55 & 0.118 & 0.112 & 112.00 & \\
\hline & 1.14 & -0.309 & 37.67 & 0.112 & 0.086 & 43.70 & 61.0 \\
\hline & 2.85 & -0.307 & 26.21 & 0.086 & 0.084 & 30.40 & 72.9 \\
\hline & 5.70 & -0.308 & 17.76 & 0.084 & 0.106 & 20.60 & 81.6 \\
\hline & 8.55 & -0.304 & 14.40 & 0.106 & 0.086 & 16.70 & 85.1 \\
\hline \multirow[t]{5}{*}{318} & 0.00 & -0.312 & 106.90 & 0.086 & 0.117 & 124.00 & \\
\hline & 1.14 & -0.305 & 50.95 & 0.117 & 0.098 & 59.10 & 56.5 \\
\hline & 2.85 & -0.305 & 36.81 & 0.098 & 0.095 & 42.70 & 68.6 \\
\hline & 5.70 & -0.308 & 24.22 & 0.095 & 0.089 & 28.10 & 79.3 \\
\hline & 8.55 & -0.301 & 19.05 & 0.089 & 0.098 & 22.10 & 83.8 \\
\hline \multirow[t]{5}{*}{323} & 0.00 & -0.311 & 117.24 & 0.098 & 0.123 & 136.00 & \\
\hline & 1.14 & -0.303 & 58.97 & 0.123 & 0.095 & 68.40 & 49.7 \\
\hline & 2.85 & -0.305 & 42.84 & 0.095 & 0.091 & 49.70 & 63.5 \\
\hline & 5.70 & -0.303 & 30.09 & 0.091 & 0.088 & 34.90 & 74.3 \\
\hline & 8.55 & -0.301 & 25.95 & 0.088 & 0.088 & 30.10 & 77.9 \\
\hline
\end{tabular}

of Nyquist plots we have decided to use equivalent circuit as given in Figure 3(a) which has been previously used to model iron/acid interface [38]. It consists of solution resistance $\left(R_{s}\right)$, charge transfer resistance $\left(R_{\mathrm{ct}}\right)$, and constant phase element (CPE). The surface roughness, degree of polycrystallinity, and also anion adsorption lead to capacitance dispersion at solid electrodes and hence the real iron/acid interface system deviates from ideal capacitive behavior, which can be empirically represented by CPE [39]. The point of intersection between inductive loop and the real axis represents $\left(R_{s}+R_{\mathrm{ct}}\right) . R_{s}$ represents solution resistance due to the ohmic resistances of corrosion product films and the solution enclosed between the working electrode and the reference electrode. $R_{\mathrm{ct}}$ represents the charge transfer resistance whose value is a measure of electron transfer across the surface and is inversely proportional to corrosion rate [40].

The Nyquists plots of aged maraging steel in $0.5 \mathrm{M}$ $\mathrm{H}_{2} \mathrm{SO}_{4}$ containing various concentrations of DAMTSC consists of two semicircles at high and middle frequency range and an inductive loop at low frequency range. These plots are analysed by an equivalent circuit, which is represented in Figure 3(b). The smaller HF capacitive loop suggested that some sort of film exists on this alloy in the studied solution which can be attributed to film formation by adsorbed inhibitor while larger middle frequency capacitive loop can be attributed to charge transfer reaction [41-44]. The resistance values corresponding to high frequency and middle frequency semicircles are represented as $R_{f}$ and $R_{\mathrm{ct}}$, respectively, in equivalent circuit Figure 3(b). Both $R_{f}$ and $R_{\mathrm{ct}}$ increase with increase in inhibitor concentration. The sum of $R_{f}$ and $R_{\mathrm{ct}}$ are taken for calculation of inhibition efficiency. The capacitance of film $\left(C_{f}\right)$ was represented by $\mathrm{CPE}_{1}$ and double layer capacitance $\left(C_{\mathrm{dl}}\right)$ was represented as $\mathrm{CPE}_{2}$. All these values are shown in Table 3. The low frequency inductive loop in inhibited acid solution might be attributed to the surface dissolution, indicating that the alloy still dissolved by the direct charge transfer at the inhibitor adsorbed steel surface [45]. The fact that this inductive loop cannot be observed at maximum concentration of DAMTSC supports this view. The study at higher temperature reveals single semicircle at low concentrations of inhibitor and appearance of two semicircles only at high concentration of 


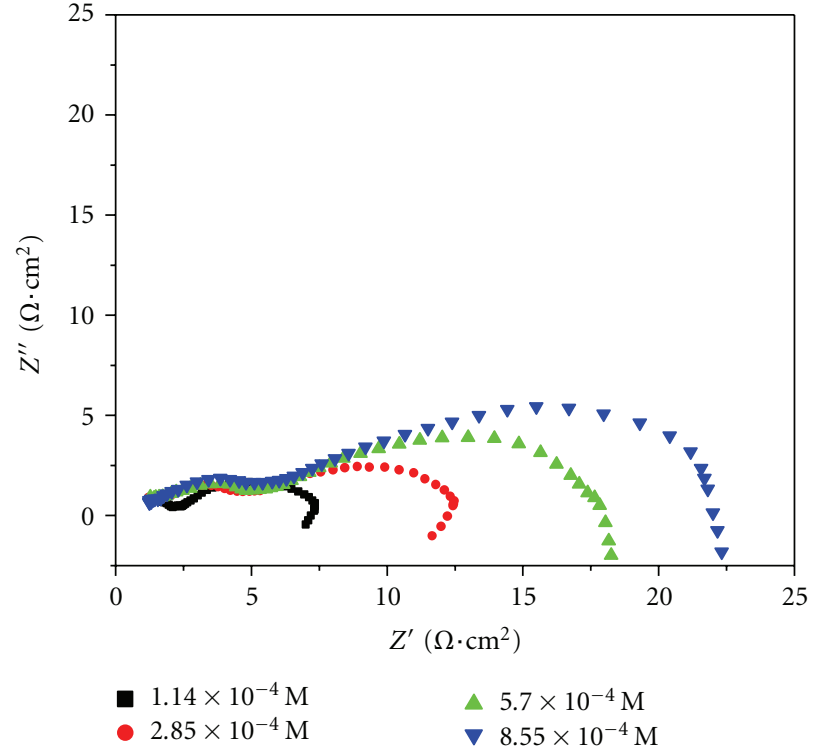

(a)

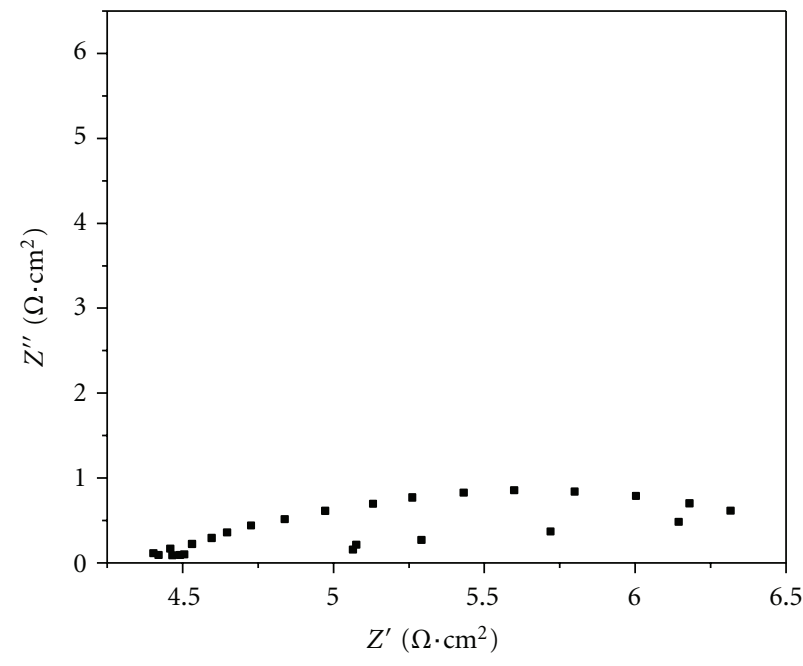

Blank

FIGURE 2: Nyquist plots for the aged maraging steel specimen in $0.5 \mathrm{M}$ sulphuric acid (a) containing different concentrations of inhibitor, (b) without inhibitor.

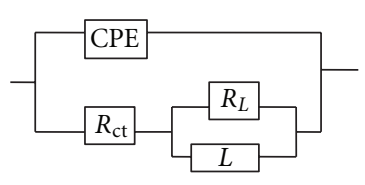

(a)

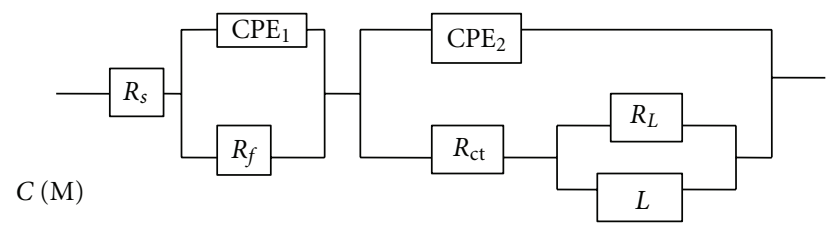

(b)

FIGURE 3: Equivalent circuit used to fit experimental EIS data for the corrosion of aged maraging steel specimen in sulphuric acid (a) without inhibitor, (b) with inhibitor.

inhibitor, this can be attributed to the fact that formation of inhibitor film is favorable only at higher inhibitor concentration above $303 \mathrm{~K}$.

The impedance of CPE is expressed as

$$
Z_{\mathrm{CPE}}=\frac{1}{Y_{0}(j w)^{n}},
$$

where the amplitude $Y_{0}$ and $n$ are frequency independent, and $\omega$ is the angular frequency for which $-Z^{\prime \prime}$ reaches its maximum values, $n$ is dependent on the surface morphology: $-1 \leq n \leq 1$. The HF loops have depressed semicircular appearance, with $0.5 \leq n \leq 1$, which is often referred to as frequency dispersion as a result of the non homogeneity or roughness [46].

The double layer capacitances $C_{\mathrm{dl}}$, for a circuit including CPE were calculated from the following equation [47]:

$$
C_{\mathrm{dl}}=Y_{0}\left(w_{\max }\right)^{n-1},
$$

where $w_{\max }=2 \pi f_{\max }$, and $f_{\max }$ is the frequency at which the imaginary component of the impedance is maximal.
According to the expression of the double layer capacitance presented in the Helmholtz model [48],

$$
C_{\mathrm{dl}}=\frac{\varepsilon \varepsilon_{0}}{d} S,
$$

where $d$ is the thickness of the film, $S$ is the surface area of the electrode, $\varepsilon_{0}$ is the permittivity of air, and $\varepsilon$ is the local dielectric constant. The value of $C_{\mathrm{dl}}$ decreases due to adsorption of inhibitor molecules, which displaces water molecules originally adsorbed on the mild steel surface and decreases the active surface area. The values of double layer capacitance decreases with increase in inhibitor concentration indicating that inhibitor molecules function by adsorption at the metal/solution interface, leading to protective film on the alloy surface, and decreasing the extent of dissolution reaction [49].

The corrosion current density $I_{\text {corr }}$ can be calculated using charge transfer resistance $R_{\mathrm{ct}}$, together with SternGeary equation [40]:

$$
I_{\text {corr }}=\frac{b_{a} b_{c}}{2.303 R_{\mathrm{ct}} A\left(b_{a}+b_{c}\right)} .
$$


TABLE 3: EIS data of aged maraging steel in $0.5 \mathrm{M}$ sulphuric acid with and without different concentrations of DAMTSC at various temperatures.

\begin{tabular}{|c|c|c|c|c|c|c|c|}
\hline Temp. (K) & $\begin{array}{c}\text { Conc. of } \\
\text { inhibitor } \\
\left(\times 10^{-4}\right)(\mathrm{M})\end{array}$ & $R_{f} \mathrm{Ohm} \cdot \mathrm{cm}^{2}$ & $R_{\mathrm{ct}} \mathrm{Ohm} \cdot \mathrm{cm}^{2}$ & $R_{\text {total }} \mathrm{Ohm} \cdot \mathrm{cm}^{2}$ & $C_{f}\left(10^{-6}\right)(\mathrm{F})$ & $C_{\mathrm{dl}}\left(10^{-6}\right)(\mathrm{F})$ & IE (\%) \\
\hline \multirow[t]{5}{*}{303} & 0.00 & & 2.8 & 2.80 & & 14490 & \\
\hline & 1.14 & 1.17 & 5.66 & 6.83 & 874 & 9920 & 59.0 \\
\hline & 2.85 & 5.37 & 9.38 & 14.75 & 799 & 9762 & 81.0 \\
\hline & 5.70 & 6.12 & 13.5 & 19.62 & 653 & 1590 & 85.7 \\
\hline & 8.55 & 7.89 & 17.8 & 25.70 & 509 & 1163 & 89.1 \\
\hline \multirow[t]{5}{*}{308} & 0.00 & & 2.30 & 2.30 & & 87620 & \\
\hline & 1.14 & & 5.10 & 5.10 & & 10112 & 54.9 \\
\hline & 2.85 & & 8.87 & 8.87 & & 7566 & 74.2 \\
\hline & 5.70 & 5.6 & 11.2 & 16.8 & 954 & 6347 & 86.3 \\
\hline & 8.55 & 7.19 & 11.6 & 18.7 & 765 & 4850 & 87.7 \\
\hline \multirow[t]{5}{*}{313} & 0.00 & & 1.6 & 1.60 & & 113500 & \\
\hline & 1.14 & & 4.32 & 3.32 & & 23724 & 51.8 \\
\hline & 2.85 & & 5.75 & 5.75 & & 20880 & 72.2 \\
\hline & 5.70 & 3.43 & 7.34 & 10.8 & 2417 & 11340 & 85.2 \\
\hline & 8.55 & 4.2 & 7.9 & 12.1 & 1450 & 10800 & 86.7 \\
\hline \multirow[t]{5}{*}{318} & 0.00 & & 1.4 & 1.4 & & 226570 & \\
\hline & 1.14 & & 2.7 & 2.7 & & 31326 & 48.1 \\
\hline & 2.85 & & 4.8 & 4.8 & & 27667 & 70.8 \\
\hline & 5.70 & 3.25 & 5.05 & 8.3 & 2625 & 23471 & 83.1 \\
\hline & 8.55 & 3.40 & 5.3 & 8.7 & 1562 & 20125 & 83.9 \\
\hline \multirow[t]{5}{*}{323} & 0.00 & & 1.3 & 1.3 & & 541000 & \\
\hline & 1.14 & & 2.3 & 2.3 & & 33540 & 43.5 \\
\hline & 2.85 & & 3.5 & 3.5 & & 24500 & 62.9 \\
\hline & 5.70 & 1.44 & 4.16 & 5.6 & 2966 & 20760 & 76.8 \\
\hline & 8.55 & 2.20 & 4.90 & 7.1 & 1695 & 15600 & 81.7 \\
\hline
\end{tabular}

The charge transfer resistance $R_{\mathrm{ct}}$ and double layer capacitance $C_{\mathrm{dl}}$ were determined by the analysis of Nyquist plot and their values are given in Table 3. The inhibition efficiency in different concentrations of DAMTSC was calculated from the charge transfer resistance according to

$$
\mathrm{IE} \%=\left(\frac{R_{\mathrm{ct}}-R_{\mathrm{ct}}^{0}}{R_{\mathrm{ct}}}\right) \times 100,
$$

where $R_{\mathrm{ct}}$ and $R_{\mathrm{ct}}^{0}$ represent the charge transfer resistance in the presence and absence of inhibitor. The values of $R_{\mathrm{ct}}$ increases with increase in inhibitor concentration and the results indicate that charge transfer process mainly controls the corrosion process. The inhibition efficiency values obtained by the electron impedance method are in good agreement with the ones obtained by Tafel's method.

3.3. Effect of Temperature. The effect of temperature on the inhibited acid-metal reaction is highly complex because many changes occur on the metal surface, such as rapid etching and desorption of the inhibitor and the inhibitor itself, and in some cases may undergo decomposition and/or rearrangement [10]. However it facilitates the calculation of many thermodynamic functions for the inhibition and/or the adsorption processes which contribute in determining the type of adsorption of the studied inhibitors. In the present study, with increase in solution temperature, corrosion potential $\left(E_{\text {corr }}\right)$, anodic Tafel slope $\left(b_{a}\right)$, and cathodic Tafel slope $\left(b_{c}\right)$ values are not affected much. This indicates that increase in temperature does not change the mechanism of corrosion reaction. But $I_{\text {corr }}$ and hence the corrosion rate of the specimen increases with increase in temperature for both blank and inhibited solutions. This may be attributed to the fact that the hydrogen evolution overpotential decreases with increase in temperature that leads to increase in cathodic reaction rate [50]. The inhibition efficiency decreases with increase in temperature which indicates desorption of inhibitor molecules [51]. This is suggestive of physisorption [52]. But this decrease is small at higher concentration of inhibitor. 


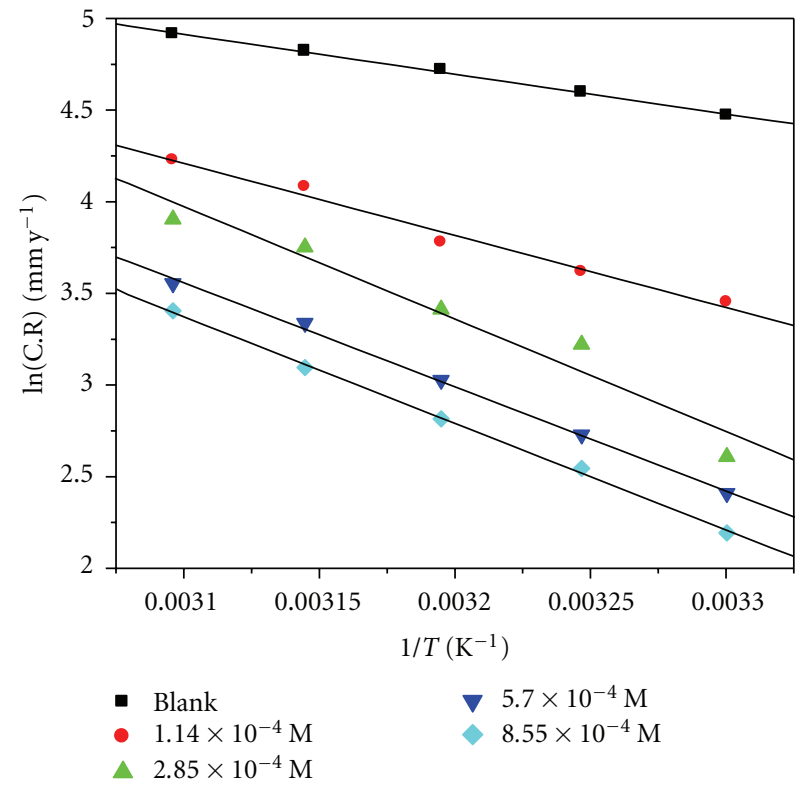

Figure 4: Arrhenious plots for the dissolution of aged maraging steel in $0.5 \mathrm{M}$ sulphuric acid containing different concentrations of inhibitor.

The apparent activation energy $\left(E_{a}\right)$ for the corrosion process in the presence and absence of inhibitor can be calculated using Arrhenius law equation [10],

$$
\ln (\mathrm{C} . \mathrm{R})=B-\left(\frac{E_{a}}{R T}\right),
$$

where $B$ is a constant which depends on the metal type and $R$ is the universal gas constant. The plot of $\ln$ (corrosion rate) versus reciprocal of absolute temperature $1 / T$ gives straight line whose slope $=-E_{a} / R$ gives activation energy for the corrosion process. The Arrhenius plots for the specimen are shown in Figure 4.

The entropy and enthalpy of activation for the dissolution of alloy, $\Delta H_{a}$ and $\Delta S_{a}$, were calculated from transition state theory equation $[10]$

$$
\mathrm{C} . \mathrm{R}=\left(\frac{R T}{N h}\right) \exp \left(\frac{\Delta S_{a}}{R}\right) \exp \left(\frac{-\Delta H_{a}}{R T}\right),
$$

where $h$ is Plank's constant, $N$ is Avagadro's number. A plot of $\ln ($ corrosion rate/T) versus $1 / T$ gives straight line with slope $=-\Delta H_{a} / R$ and intercept $=\ln (R / N h)+\Delta S_{a} / R$. The calculated values of $E_{a}, \Delta H_{a}$, and $\Delta S_{a}$ are given in Table 4 . The plot of $\ln$ (corrosion rate/T) versus $1 / T$ for aged samples of maraging steel is shown in Figure 5.

The effect of chemically stable surface active inhibitors is to increase the energy of activation and to decrease the surface area available for corrosion [53]. The value of activation energy $\left(E_{a}\right)$ in $0.5 \mathrm{M}$ sulphuric acid solution containing inhibitor is greater than that without inhibitor. The extent of increase is proportional to the inhibitor concentration, indicating that the energy barrier for the corrosion reaction increases with increase in DAMTSC concentration.
TABLE 4: Activation parameters for the corrosion of aged maraging steel in $0.5 \mathrm{M}$ sulphuric acid with and without different concentrations of DAMTSC.

\begin{tabular}{lccc}
\hline $\begin{array}{l}\text { Conc. of } \\
\text { inhibitor } \\
\left(\times 10^{-4}\right)(\mathrm{M})\end{array}$ & $\begin{array}{c}E_{a} \\
\mathrm{~kJ} \mathrm{~mol}^{-1}\end{array}$ & $\begin{array}{c}\Delta H_{a} \\
\mathrm{~kJ} \mathrm{~mol}^{-1}\end{array}$ & $\begin{array}{c}\Delta S_{a} \\
\mathrm{~J} \mathrm{~mol}^{-1} \mathrm{~K}^{-1}\end{array}$ \\
\hline 0 & 18.1 & 15.5 & -156.7 \\
1.14 & 32.7 & 30.1 & -117.3 \\
2.85 & 47.3 & 44.6 & -77.7 \\
5.70 & 48.4 & 45.8 & -75.7 \\
8.55 & 51.1 & 48.4 & -62.5 \\
\hline
\end{tabular}

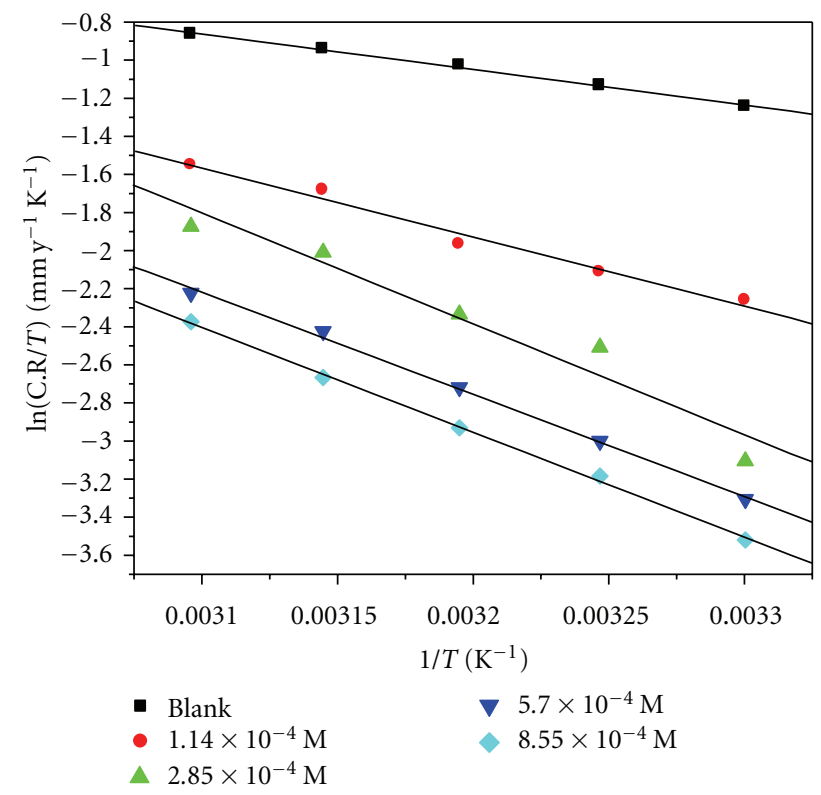

FIGURE 5: $\ln$ (corrosion rate/ $T$ ) versus $1 / T$ for aged maraging steel in $0.5 \mathrm{M}$ sulphuric acid containing different concentrations of inhibitor.

The increase in apparent activation energy $E_{a}$ may be interpreted as due to physical adsorption [54] of the inhibitor, which results in increase in surface coverage with the increase in the concentration of the inhibitor. The decrease in the inhibition efficiency of DAMTSC with increase in temperature can be attributed to an appreciable decrease in the adsorption of the inhibitor on the metal surface with increase in temperature and a corresponding increase in corrosion rate due to the fact that greater area of metal is exposed to the acid [55].

The values of entropy of activation in the absence and presence of inhibitor are large and negative. This implies that the activated complex in the rate determining step represents an association rather than dissociation step, resulting in a decrease in randomness on going from reactants to activated complex [56, 57]. The entropy of activation values are more for inhibited solutions than that for the uninhibited solutions. This suggested that an increase in randomness occurred on going from reactants to the activated complex. This might be the results of the adsorption of organic 
inhibitor molecules from the acidic solution which could be regarded as a quasi-substitution process between the organic compound in the aqueous phase and water molecules at electrode surface $[58,59]$. In this situation, the adsorption of organic inhibitor is accompanied by desorption of water molecules from the surface. Thus the increasing in entropy of activation was attributed to the increase in solvent entropy [60].

3.4. Adsorption Isotherm. Organic corrosion inhibitors are known to decrease metal dissolution via adsorption on the metal/corrodent interface to form a protective film which separates the metal surface from the corrosive medium. The adsorption route is usually regarded as a substitution process between the organic inhibitor in the aqueous solution $\left[\operatorname{Inh}_{(\mathrm{sol})}\right]$ and water molecules adsorbed at the metal surface $\left[\mathrm{H}_{2} \mathrm{O}_{(\mathrm{ads})}\right]$ as follows [61]:

$$
\operatorname{Inh}_{(\mathrm{sol})}+\chi \mathrm{H}_{2} \mathrm{O}_{(\mathrm{ads})} \longleftrightarrow \operatorname{Inh}_{(\mathrm{ads})}+\chi \mathrm{H}_{2} \mathrm{O}_{(\mathrm{sol})},
$$

where $\chi$ represents the number of water molecules replaced by one molecule of adsorbed inhibitor. The adsorption bond strength is dependent on the composition of the metal, corrodent, inhibitor structure, concentration, and orientation as well as temperature. Basic information on the interaction between the inhibitor and alloy surface can be provided by adsorption isotherm. In order to obtain isotherm, the linear relation between surface coverage $(\theta)$ value and $C_{\text {inh }}$ must be found. The surface coverage $\theta$ is given by

$$
\theta=\frac{\mathrm{IE} \%}{100},
$$

where IE\% is percentage inhibition efficiency as calculated using (2).

Attempts were made to fit the degree of surface coverage $(\theta)$ values to various isotherms including Langmuir, Temkin, Frumkin, and Flory-Huggins isotherms. By far the best fit is obtained with the modified Langmuir adsorption isotherm. Langmuir isotherm for monolayer chemisorption is given by

$$
\frac{C_{\mathrm{inh}}}{\theta}=\frac{1}{K_{\mathrm{ads}}}+C_{\mathrm{inh}}
$$

where $C_{\mathrm{inh}}$ is the concentration of inhibitor, $K_{\mathrm{ads}}$ is the equilibrium constant for adsorption process, and $\theta$ is the degree of the surface coverage which is calculated using (11).

This model has also been used for other inhibitor systems [61]. The plot of $C_{\mathrm{inh}} / \theta$ versus $C_{\mathrm{inh}}$ gives a straight line with intercept $1 / K_{\mathrm{ads}}$ as shown in Figure 6.

The values of standard free energy of adsorption are related to $K_{\mathrm{ads}}$ by the relation (13).

$$
K_{\mathrm{ads}}=\frac{1}{55.5} e^{\left(-\Delta G_{\mathrm{ads}}^{0} / R T\right)},
$$

where the value 55.5 is the concentration of water in solution in $\mathrm{M}(\mathrm{mol} / \mathrm{L}), R$ is the universal gas constant and $T$ is absolute temperature [61]. The thermodynamic data obtained from adsorption isotherm are tabulated in Table 5. The correlation coefficient $\left(R^{2}\right)$ was used to choose the isotherm

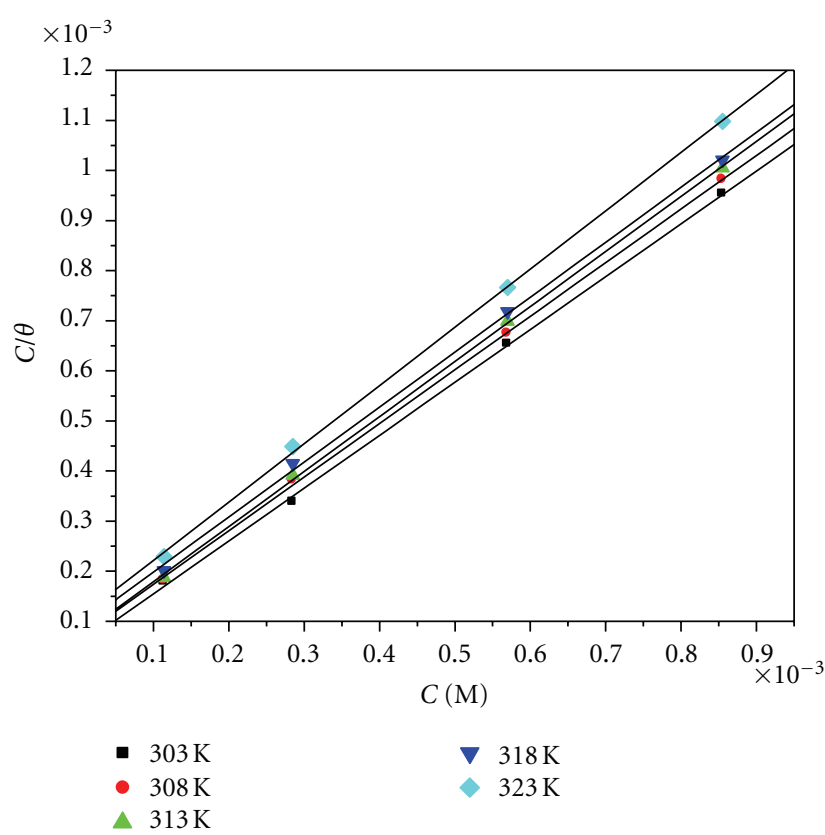

FIGURE 6: Langmuir adsorption isotherm of DAMTSC on aged maraging steel in $0.5 \mathrm{M}$ sulphuric acid at different temperatures.

that best fit experimental data [10]. The linear regression coefficients are close to unity and the slopes of straight lines are nearly unity, suggesting that the adsorption of DAMTSC obeys Langmuir's adsorption isotherm and there is negligible interaction between the adsorbed molecules [26]. The high values of $K_{\mathrm{ads}}$ for the studied inhibitor indicate strong adsorption of inhibitor on the alloy surface. Negative values of $\Delta G_{\mathrm{ads}}^{0}$ are characteristic feature of strong spontaneous adsorption for the studied compounds, which also reflect the high values of inhibition. The negative $\Delta G_{\text {ads }}^{0}$ values calculated from (13) are consistent with the spontaneity of the adsorption process and the stability of the adsorbed layer on the maraging steel surface. Generally, the standard free energy values of $-20 \mathrm{~kJ} \mathrm{~mol}^{-1}$ or less negative are associated with an electrostatic interaction between charged molecules and charged metal surface, resulting in physisorption and those of $-40 \mathrm{~kJ} \mathrm{~mol}^{-1}$ or more negative involve charge sharing or transfer from the inhibitor molecules to the metal surface to form a coordinate covalent bond, resulting in chemisorption [62]. The $\Delta G_{\text {ads }}^{0}$ values obtained for the studied inhibitor on the alloy surface in $0.5 \mathrm{M}$ sulphuric acid are -33 to $-35 \mathrm{~kJ} / \mathrm{mol}$. These values predict both physical and chemical adsorption of inhibitor [63]. A plot of $\Delta G_{\text {ads }}^{0}$ versus $T$ was used to calculate heat of adsorption $\Delta H_{\text {ads }}^{0}$ and the standard adsorption entropy $\Delta S_{\text {ads }}^{0}$ according to the following thermodynamic basic equation [10]:

$$
\Delta G_{\mathrm{ads}}^{0}=\Delta H_{\mathrm{ads}}^{0}-T \Delta S_{\mathrm{ads}}^{0} .
$$

The thermodynamic data obtained for DAMTSC using Langmuir adsorption isotherm are depicted in Table 5.

The values of thermodynamic parameters for the adsorption of inhibitors can provide valuable information about the mechanism of corrosion inhibition. While an 
TABLE 5: Thermodynamic parameters for the adsorption of DAMTSC on aged maraging steel surface in $0.5 \mathrm{M}$ sulphuric acid.

\begin{tabular}{lccccc}
\hline $\begin{array}{l}\text { Temperature } \\
\left({ }^{\circ} \mathrm{C}\right)\end{array}$ & $\mathrm{K}\left(\mathrm{mol}^{-1} \mathrm{~L}\right)$ & $\begin{array}{c}-\Delta G_{\mathrm{ads}}^{0} \\
\mathrm{~kJ} \mathrm{~mol}^{-1}\end{array}$ & $R^{2}$ & Slope & $\begin{array}{c}\Delta H_{\mathrm{ads}}^{0} \\
\mathrm{kJol}^{-1}\end{array}$ \\
\hline 303 & 20227 & 35.1 & 0.9997 & 1.05 & $\begin{array}{c}\Delta S_{\mathrm{ads}}^{0} \\
\mathrm{~J} \mathrm{~mol}^{-1} \mathrm{~K}^{-1}\end{array}$ \\
308 & 14931 & 34.3 & 0.9997 & 1.07 & -62.25 \\
313 & 14391 & 34.2 & 0.9997 & 1.09 & 90 \\
318 & 11246 & 33.6 & 0.9995 & 1.09 & 1.14 \\
323 & 9476.9 & 33.2 & 0.9997 & & \\
\hline
\end{tabular}

endothermic adsorption process $\left(\Delta H_{\mathrm{ads}}^{0}>0\right)$ is attributed unequivocally to chemisorption [64], an exothermic adsorption process $\left(\Delta H_{\text {ads }}^{0}<0\right)$ may involve either physisorption or chemisorption or a mixture of both the processes. In an exothermic process, physisorption is distinguished from chemisorption by considering the absolute value of adsorption enthalpy. Typically, the enthalpy of a physisorption process is below $41.86 \mathrm{~kJ} \mathrm{~mol}^{-1}$, while that of a chemisorption process approaches $100 \mathrm{~kJ} \mathrm{~mol}^{-1}$ [65]. In the present case, the calculated value of $\Delta H_{\mathrm{ads}}^{0}$ is $-69.014 \mathrm{~kJ} \mathrm{~mol}^{-1}$, which is an intermediate case [63], probably involving both physisorption and chemisorption. The $\Delta S_{\text {ads }}^{0}$ value is large and negative, indicating that decrease in disordering takes place on going from reactant to alloy adsorbed species. This can be attributed to the fact that adsorption is an exothermic process and is always accompanied by decrease in entropy.

3.5. Mechanism of Corrosion Inhibition. In order to predict the type of adsorption, the corrosion mechanism of iron must be known. It was suggested that the anodic dissolution of iron in sulphuric acid solutions follow the consecutive or BDD mechanism [66] as reported by [41]. Iron electro dissolution in acidic sulphate solution depends primarily on the adsorbed intermediate $\mathrm{FeOH}_{\text {ads }}$ according to the mechanism reproduced below:

$$
\begin{aligned}
\mathrm{FeH}_{2} \mathrm{O}_{\mathrm{ads}} & \Longleftrightarrow \mathrm{FeOH}_{\mathrm{ads}}+\mathrm{H}^{+}+\mathrm{e} \\
\mathrm{FeOH}_{\mathrm{ads}} & \longrightarrow \mathrm{FeOH}^{+}+\mathrm{e} \\
\mathrm{FeOH}^{+}+\mathrm{H}^{+} & \Longleftrightarrow \mathrm{Fe}^{2+}+2 \mathrm{e}
\end{aligned}
$$

The following stages are possible for the hydrogen evolution reaction on iron [67]:

$$
\begin{gathered}
\mathrm{Fe}+\mathrm{H}^{+}+\mathrm{e}^{-} \longrightarrow \mathrm{FeH} \\
\mathrm{FeH}+\mathrm{FeH} \longrightarrow 2 \mathrm{Fe}+\mathrm{H}_{2} \\
\mathrm{FeH}+\mathrm{H}^{+}+\mathrm{e}^{-} \longrightarrow \mathrm{Fe}+\mathrm{H}_{2}
\end{gathered}
$$

The corrosion rate of iron in $\mathrm{H}_{2} \mathrm{SO}_{4}$ solutions is controlled by both hydrogen evolution reaction and iron dissolution.
An anodic oxidation mechanism in the presence of inhibitor may be similar to the mechanism discussed by McCafferty et al. [68-70] as reported by [71]. Consider

$$
\begin{aligned}
\mathrm{Fe}+\mathrm{H}_{2} \mathrm{O} & \Leftrightarrow \mathrm{Fe} \cdot \mathrm{H}_{2} \mathrm{O}_{\mathrm{ads}} \\
\mathrm{Fe} \cdot \mathrm{H}_{2} \mathrm{O}_{\mathrm{ads}}+\mathrm{Y} & \Leftrightarrow \mathrm{FeOH}_{\text {ads }}^{-}+\mathrm{H}^{+}+\mathrm{Y} \\
\mathrm{Fe} \cdot \mathrm{H}_{2} \mathrm{O}_{\mathrm{ads}}+\mathrm{Y} & \Leftrightarrow \mathrm{FeY}_{\mathrm{ads}}+\mathrm{H}_{2} \mathrm{O} \\
\mathrm{FeOH} & \longrightarrow \mathrm{FeOH}_{\mathrm{ads}}+\mathrm{e} \text { (rate determining step) } \\
\mathrm{FeY}_{\mathrm{ads}} & \Leftrightarrow \mathrm{FeY}_{\mathrm{ads}}^{+}+\mathrm{e} \\
\mathrm{FeOH}_{\mathrm{ads}}+\mathrm{FeY}_{\mathrm{ads}}^{+} & \Leftrightarrow \mathrm{FeOH}^{+}+\mathrm{FeY}_{\mathrm{ads}} \\
\mathrm{FeOH}^{+}+\mathrm{H}^{+} & \Leftrightarrow \mathrm{Fe}^{2+}+\mathrm{H}_{2} \mathrm{O}
\end{aligned}
$$

where $\mathrm{Y}$ is inhibitor molecule.

According to the above mechanism, displacement of some adsorbed water molecules on the metal surface by inhibitor species to yield the adsorbed intermediate $\mathrm{FeY}_{\mathrm{ads}}$ in step (23) reduces the amount of the species $\mathrm{FeOH}_{\mathrm{ads}}^{-}$ available for the rate determining step. The inhibitor used may form dominating adsorbed intermediate which results in inhibitive effects. This conclusion is in line with those of Obot and Obi-Egbedi [72], and Shoesmith [73]. Aged maraging steel results from precipitation of intermetallics. Since these intermetallics have different composition, their electrochemical behavior is expected to be different compared to matrix [74]. Also there will be strain fields around these coherent precipitates as a result of lattice mismatch between the precipitate and the matrix due to the difference in the crystal structure and lattice parameters. These strain fields in combination with the galvanic effect due to the composition difference leads to the enhanced corrosion of aged maraging steel in acid medium. Considering the inhomogeneous nature, the surface of alloy is generally characterized by multiple adsorption sites having activation energies and heats of adsorption. Inhibitor molecules may thus be adsorbed more readily at surface active sites having suitable adsorption enthalpies.

The adsorption mechanism for a given inhibitor depends on factors such as, the nature of metal, the corrosive medium, the $\mathrm{pH}$, and the concentration of the inhibitor as well as the functional groups present in its molecule, since different groups are adsorbed to different extents. For instance Scontaining substances have been shown to preferentially 


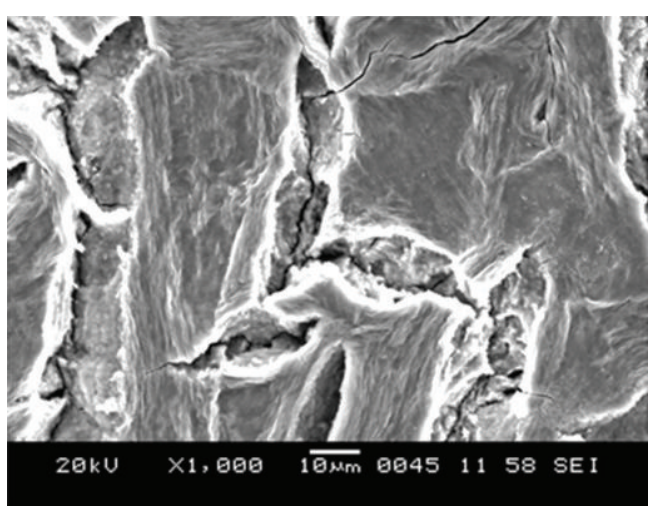

(a)

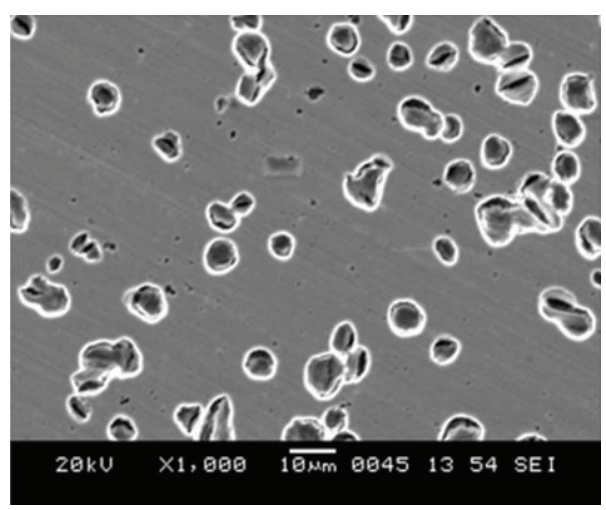

(b)

FIGURE 7: SEM image of the aged maraging steel after immersion in (a) $0.5 \mathrm{M}$ sulphuric acid without inhibitor, (b) $0.5 \mathrm{M}$ sulphuric acid containing DAMTSC.

chemisorb on the surface of iron in acidic medium, whereas $\mathrm{N}$-containing substances tend to favor physisorption [75]. It is reported that protective value of sulphur containing compounds is superior to that of nitrogen containing compounds. This may be due to greater polarizability of sulphur atom and the presence of two electron pairs available for coordination [22].

The inhibition effect of DAMTSC in sulphuric acid solution can be explained as follows: DAMTSC might be protonated in the acid solution as follows:

$$
\text { DAMTSC }+x \mathrm{H}^{+} \longrightarrow\left[\text { DAMTSCH}_{x}\right]^{x+}
$$

Thus in aqueous acidic solution, DAMTSC exists partly in the form of protonated species and partly as neutral molecules. Generally two modes of adsorption could be considered. Taking into consideration of many reported results Hackerman et al. [76] concluded that, the surface charge of iron in sulphuric acid solution at the free corrosion potential is positive. Therefore, the adsorption of protonated species would be through electrostatic attraction between the positively charged molecule and the negatively charged sulphate ions adsorbed on the metal surface via physisorption. In the study of the effect of inorganic anions and organic compounds on corrosion inhibition of mild steel in various acids, $\mathrm{Li}$ et al. [77] reported the degree of adsorption of anions was in the order $\mathrm{I}^{-}>\mathrm{Br}^{-}>\mathrm{Cl}^{-}>\mathrm{SO}_{4}{ }^{2-}>\mathrm{ClO}^{4-}$. The sulphate ions with low degree of adsorption could not cover the metal surface fully and therefore there is always possibility of the neutral inhibitor molecules occupying the vacant adsorption sites on the metal surface via the chemisorption mode of protection of corroding surface [78]. The possible bonding sites of the neutral inhibitor are the free electron pairs on sulphur and nitrogen atoms, as well as oxygen, which could interact with vacant d orbital of iron [78].

3.6. Scanning Electron Microscope Studies (SEM). The scanning electron microscope images were recorded to establish the interaction of acid medium with the metal surface. The surface morphology of the aged samples was examined by SEM immediately after the sample is subjected to corrosion tests in $\mathrm{H}_{2} \mathrm{SO}_{4}$ medium in the absence and in the presence of inhibitor. The SEM image of corroded aged maraging steel sample in Figure 7(a) shows degradation of alloy in the absence of inhibitor. The attack by $\mathrm{H}_{2} \mathrm{SO}_{4}$ is seen to be more at grain boundary since these regions are highly susceptible to corrosion. In aged samples the intermetallic precipitation at grain boundary may be responsible for the higher rate of corrosion. Figure 7(b) represents SEM image of aged maraging steel after the corrosion tests in a medium of sulphuric acid containing DMBTSC. The image clearly shows the adsorbed layer of inhibitor molecules on the alloy surface thus protecting the metal from corrosion.

\section{Conclusions}

Potentiodynamic polarization and electrochemical impedance methods were used to evaluate the ability of DAMTSC to inhibit corrosion of aged maraging steel in $0.5 \mathrm{M}$ sulphuric acid. The principle conclusions are as follows.

(1) The corrosion of aged maraging steel in $0.5 \mathrm{M}$ sulphuric acid is significantly reduced by the addition of DAMTSC even at low concentration.

(2) The inhibition efficiency increases with increase in inhibitor concentration.

(3) The inhibition efficiency decreases with increase in temperature of medium.

(4) DAMTSC acts as mixed type inhibitor, affecting both anodic and cathodic reactions.

(5) The adsorption of DAMTSC on aged maraging steel surface obeys Langmuir's adsorption isotherm model.

(6) The negative value of $\Delta G_{\text {ads }}^{0}$ obtained indicates that DAMTSC adsorbed spontaneously on the aged maraging steel. The adsorption process is exothermic and accompanied by decrease in entropy.

(7) The $\Delta G_{\text {ads }}^{0}$ and $\Delta H_{\text {ads }}^{0}$ values predict both physisorption and chemisorption of inhibitor on alloy surface. 
(8) SEM images revealed protection of alloy surface in sulphuric acid medium by the adsorption of DAMTSC.

(9) The inhibition efficiencies obtained from potentiodynamic polarization and EIS techniques are in reasonably good agreement.

\section{References}

[1] K. Y. Sastry, R. Narayanan, C. R. Shamantha et al., "Stress corrosion cracking of maraging steel weldments," Materials Science and Technology, vol. 19, no. 3, pp. 375-381, 2003.

[2] K. Rohrbach and M. Schmidt, Properties and Selection: Irons, Steels, and High-Performance Alloys, vol. 1 of ASM Handbook, 10th edition, 1990.

[3] W. W. Kirk, R. A. Covert, and T. P. May, "Corrosion behaviour of high-strength steels in marine environment," Metals Engineering Quarterly, vol. 8, pp. 31-38, 1968.

[4] S. W. Dean and H. R. Copson, "Stress corrosion behaviour of maraging steel in natural environments," Corrosion, vol. 21, pp. 95-103, 1965.

[5] Data bulletin on $18 \% \mathrm{Ni}$ maraging steel. The International Nickel Company, INC, 1964.

[6] J. Rezek, I. E. Klein, and J. Yhalom, "Electrochemical properties of protective coatings on maraging steel," Corrosion Science, vol. 39, pp. 385-397, 1997.

[7] P. P. Sinha, "Design and development of new variety of 250 grade stainless steel maraging steel," Transactions of The IIM, vol. 35, article 2, 1982.

[8] T. Poornima, N. Jagannatha, and A. Nityananda Shetty, "Studies on corrosion of annealed and aged $18 \mathrm{Ni} 250$ grade maraging steel in sulphuric acid medium," Portugaliae Electrochimica Acta, vol. 28, no. 3, pp. 173-188, 2010.

[9] T. Poornima, J. Nayak, and A. Nityananda Shetty, "3,4-Dimethoxybenzaldehydethiosemicarbazone as corrosion inhibitor for aged $18 \mathrm{Ni} 250$ grade maraging steel in $0.5 \mathrm{M}$ sulfuric acid," Journal of Applied Electrochemistry, vol. 41, no. 2, pp. 223-233, 2011.

[10] F. Bentiss, M. Lebrini, and M. Lagrenee, "Thermodynamic characterization of metal dissolution and inhibitor adsorption processes in mild steel/2. 5-bis(n-thienyl)-1. 3. 4thiadiazoles/hydrochloric acidsystem," Corrosion Science, vol. 47, pp. 2915-2931, 2005.

[11] M. Lebrini, F. Bentiss, H. Vezin, and M. Lagrenée, "The inhibition of mild steel corrosion in acidic solutions by 2,5-bis(4-pyridyl)-1,3,4-thiadiazole: structure-activity correlation," Corrosion Science, vol. 48, no. 5, pp. 1279-1291, 2006.

[12] P. Lowmunkhong, D. Ungthararak, and P. Sutthivaiyakit, "Tryptamine as a corrosion inhibitor of mild steel in hydrochloric acid solution," Corrosion Science, vol. 52, no. 1, pp. 30-36, 2010.

[13] S. Sankarapapavinasam, F. Pushpanaden, and M. F. Ahmed, "Piperidine, piperidones and tetrahydrothiopyrones as inhibitors for the corrosion of copper in $\mathrm{H}_{2} \mathrm{SO}_{4}$," Corrosion Science, vol. 32, no. 2, pp. 193-203, 1991.

[14] G. Schmitt, "Application of inhibitors for acid media. Report Prepared for the European Federation of Corrosion Working Party on Inhibitors," British Corrosion Journal, vol. 19, pp. 165-176, 1984.

[15] S. Singh, F. Athar, and A. Azam, "Synthesis, spectral studies and in vitro assessment for antiamoebic activity of new cyclooctadiene ruthenium(ii) complexes with 5nitrothiophene-2-carboxaldehyde thiosemicarbazones," Bioorganic and Medicinal Chemistry Letters, vol. 15, pp. 54245428, 2005.

[16] B. O. Renata, M. S. F. Elaine, P. P. S. Rodrigo, A. A. Anderson, U. K. Antoniana, and L. Z. Carlos, "Synthesis and antimalarial activity of semicarbazone and thiosemicarbazone derivatives," European Journal of Medicinal Chemistry, vol. 43, p. 1984, 2008.

[17] J. Easmon, G. Heinisch, W. Holzer, and B. Rosenwirth, "Novel thiosemicarbazones derived from formyl- and acyldiazines: synthesis, effects on cell proliferation, and synergism with antiviral agents," Journal of Medicinal Chemistry, vol. 35, no. 17, pp. 3288-3296, 1992.

[18] O. Efanga Offiong and S. Martelli, "Antifungal and antibacterial activity of 2-acetylpyridine-(4-phenylthiosemicarbazone) and its metal (II) complexes," Farmaco, vol. 47, no. 12, pp. 1543-1554, 1992.

[19] O. E. Offiong and S. Martelli, "Synthesis, antibacterial and antifungal activity of metal (II) complexes of 2-acetylpyridine thiosemicarbazones," Farmaco, vol. 48, no. 6, pp. 777-793, 1993.

[20] S. T. Arab, "Inhibition action of thiosemicabazone and some of it is $\rho$-substituted compounds on the corrosion of ironbase metallic glass alloy in $0.5 \mathrm{M} \mathrm{H}_{2} \mathrm{SO}_{4}$ at $30^{\circ} \mathrm{C}$," Materials Research Bulletin, vol. 43, pp. 510-521, 2008.

[21] B. A. Abd El-Nabey, E. Khamis, G. E. Thompson, and J. L. Dawson, "Effect of temperature on the inhibition of the acid corrosion of steel by benzaldehyde thiosemicarbazone: impedance measurements," Surface and Coatings Technology, vol. 28, no. 1, pp. 83-91, 1986.

[22] E. E. Ebenso, U. J. Ekpe, B. I. Ita, O. E. Offiong, and U. J. Ibok, "Effect of molecular structure on the efficiency of amides and thiosemicarbazones used for corrosion inhibition of mild steel in hydrochloric acid," Materials Chemistry and Physics, vol. 60, no. 1, pp. 79-90, 1999.

[23] K. Stanly Jacob and G. Parameswaran, "Corrosion inhibition of mild steel in hydrochloric acid solution by Schiff base furoin thiosemicarbazone," Corrosion Science, vol. 52, no. 1, pp. 224$228,2010$.

[24] A. Riose and M. Valcarcel, "Homogeneous precipitation of palladium dimethylglyoximate by interchange reactions of C=N groups," Analyst, vol. 107, pp. 737-743, 1982.

[25] M. G. Fontana, Corrosion Engineering, McGraw-Hill, Singapore, 3rd edition, 1987.

[26] W. H. Li, Q. He, S. T. Zhang, C. L. Pei, and B. R. Hou, "Some new triazole derivatives as inhibitors for mild steel corrosion in acidic medium," Journal of Applied Electrochemistry, vol. 38, no. 3, pp. 289-295, 2008.

[27] C. Cao, "On electrochemical techniques for interface inhibitor research," vol. 38, no. 12, pp. 2073-2082, 1996.

[28] A. R. El-Sayed, A. M. Shaker, and H. M. Abd El-Lateef, "Corrosion inhibition of tin, indium and tin-indium alloys by adenine or adenosine in hydrochloric acid solution," Corrosion Science, vol. 52, no. 1, pp. 72-81, 2010.

[29] S. S. Abd El-Rehim, H. H. Hassan, and M. A. Amin, "Corrosion inhibition study of pure $\mathrm{Al}$ and some of its alloys in $1.0 \mathrm{M} \mathrm{HCl}$ solution by impedance technique," Corrosion Science, vol. 46, pp. 5-25, 2004.

[30] W. Li, Q. He, C. Pei, and B. Hou, "Experimental and theoretical investigation of the adsorption behaviour of new triazole derivatives as inhibitors for mild steel corrosion in acid media," Electrochimica Acta, vol. 52, pp. 6386-6394, 2007. 
[31] W. J. Lorenz and F. Mansfeld, "Determination of corrosion rates by electrochemical DC and AC methods," Corrosion Science, vol. 21, pp. 647-672, 1982.

[32] A. A. Aksut, W. J. Lorenz, and F. Mansfeld, "The determination of corrosion rates by electrochemical d.c. and a.c. methods2. Systems with discontinuous steady state polarization behavior," Corrosion Science, vol. 22, pp. 611-619, 1982.

[33] Q. Qu, Z. Hao, L. Li, W. Bai, Y. Liu, and Z. Ding, "Synthesis and evaluation of Tris-hydroxymethyl-(2-hydroxybenzylidenamino)-methane as a corrosion inhibitor for cold rolled steel in hydrochloric acid," Corrosion Science, vol. 51, no. 3, pp. 569-574, 2009.

[34] G. Quartarone, L. Ronchin, A. Vavasori, C. Tortato, and L. Bonaldo, "Inhibitive action of gramine towards corrosion of mild steel in deaerated 1.0 M hydrochloric acid solutions," Corrosion Science, vol. 64, pp. 82-89, 2012.

[35] I. Ahamad, R. Prasad, and M. A. Quraishi, "Adsorption and inhibitive properties of some new Mannich bases of Isatin derivatives on corrosion of mild steel in acidic media," Corrosion Science, vol. 52, no. 4, pp. 1472-1481, 2010.

[36] M. A. Veloz and I. Gonzalez, "Electrochemical study of carbon steel corrosion in buffered acetic acid solutions with chlorides and $\mathrm{H}_{2}$ S," Electrochimica Acta, vol. 48, pp. 135-144, 2002.

[37] E. M. Sherif and S. M. Park, "Effects of 1, 4-naphthoquinone on aluminum corrosion in $0.50 \mathrm{M}$ sodium chloride solutions," Electrochimica Acta, vol. 51, pp. 1313-1321, 2006.

[38] A. Popova, E. Sokolova, S. Raicheva, and M. Christov, "AC and DC study of the temperature effect on mild steel corrosion in acid media in the presence of benzimidazole derivatives," Corrosion Science, vol. 45, no. 1, pp. 33-58, 2003.

[39] E. Barsoukov and J. R. Macdonald, Impedance Spectroscopy Theory, Experiment, and Applications, John Wiley \& Sons, 2nd edition, 2005.

[40] A. El-Sayed, "Phenothiazine as inhibitor of the corrosion of cadmium in acidic solutions," Journal of Applied Electrochemistry, vol. 27, pp. 193-200, 1997.

[41] A. Popova, M. Christov, and A. Vasilev, "Mono- and dicationic benzothiazolic quaternary ammonium bromides as mild steel corrosion inhibitors-part 2: electrochemical impedance and polarisation resistance results," Corrosion Science, vol. 53, no. 5, pp. 1770-1777, 2011.

[42] B. Seshu, A. K. Bhatnagar, A. Venugopal, and V. S. Raja, "Electrochemical corrosion behaviours of $\mathrm{Fe}_{68} \mathrm{Ni}_{14-x} \mathrm{Mo}_{x} \mathrm{Si}_{2} \mathrm{~B}_{16}$ metallic glasses in $1 \mathrm{~N} \mathrm{HCl}$ and $1 \mathrm{~N} \mathrm{H}_{2} \mathrm{SO}_{4}$," Journal of Materials Science, vol. 32, pp. 2071-2075, 1997.

[43] S. T. Arab and K. M. Emran, "Structure effect of some thiosemicarbazone derivatives on the corrosion inhibition of $\mathrm{Fe}_{78} \mathrm{~B}_{13} \mathrm{Si}_{9}$ glassy alloy in $\mathrm{Na}_{2} \mathrm{SO}_{4}$ solution," Materials Letters, vol. 62, no. 6-7, pp. 1022-1032, 2008.

[44] H. Ashassi-Sorkabi, T. A. Aliyev, S. Nasiri, and R. Zarepoor, Electrochimica Acta, vol. 52, p. 5240, 2007.

[45] M. A. Amin, K. F. Khaled, and S. A. Fadl-Allah, "Testing validity of the Tafel extrapolation method for monitoring corrosion of cold rolled steel in $\mathrm{HCl}$ solutions-experimental and theoretical studies," Corrosion Science, vol. 52, no. 1, pp. 140-151, 2010.

[46] H. H. Hassan, E. Abdelghani, and M. A. Amin, "Inhibition of mild steel corrosion in hydrochloric acid solution by triazole derivatives-part I. Polarization and EIS studies," Electrochimica Acta, vol. 52, pp. 6359-6364, 2007.

[47] C. H. Hsu and F. Mansfeld, "Concernng the conversion of the constant phase element parameter Y0 into a capacitance," Corrosion, vol. 57, no. 9, pp. 747-748, 2001.
[48] E. McCafferty and N. Hackerman, "Double layer capacitance of iron and corrosion inhibition with polymethylene diamines," Journal of The Electrochemical Society, vol. 119, pp. 146-154, 1972.

[49] F. Bentiss, M. Traisnel, and M. Lagrenee, "The substituted 1,3,4-oxadiazoles: a new class of corrosion inhibitors of mild steel in acidic media," Corrosion Science, vol. 42, no. 1, pp. 127$146,2000$.

[50] L. Larabi, Y. Harek, O. Benali, and S. Ghalem, "Hydrazide derivatives as corrosion inhibitors for mild steel in $1 \mathrm{M} \mathrm{HCl}$," Progress in Organic Coatings, vol. 54, p. 261, 2005.

[51] M. Schorr and J. Yahalom, "The significance of the energy of activation for the dissolution reaction of metal in acids," Corrosion Science, vol. 12, no. 11, pp. 867-868, 1972.

[52] M. M. Solomon, S. A. Umoren, I. I. Udosoro, and A. P. Udoh, "Inhibitive and adsorption behaviour of carboxymethyl cellulose on mild steel corrosion in sulphuric acid solution," Corrosion Science, vol. 52, no. 4, pp. 1317-1325, 2010.

[53] L. Antropov, "A correlation between kinetics of corrosion and the mechanism of inhibition by organic compounds," Corrosion Science, vol. 7, pp. 607-620, 1967.

[54] E. F. E. Sherbini, "Effect of some ethoxylated fatty acids on the corrosion behaviour of mild steel in sulphuric acid solution," Materials Chemistry and Physics, vol. 60, pp. 286-290, 1999.

[55] T. Szauer and A. Brand, "On the role of fatty acid in adsorption and corrosion inhibition of iron by amine-fatty acid salts in acidic solution," Electrochimica Acta, vol. 26, pp. 1257-1260, 1981.

[56] M. K. Gomma and M. H. Wahdan, "Schiff bases as corrosion inhibitors for aluminium in hydrochloric acid solution," Materials Chemistry and Physics, vol. 39, pp. 209-213, 1995.

[57] J. Marsh, Advanced Organic Chemistry, Wiley Eastern, New Delhi, India, 3rd edition, 1988.

[58] M. Sahin, S. Bilgic, and H. Yilmaz, "The inhibition effects of some cyclic nitrogen compounds on the corrosion of the steel in $\mathrm{NaCl}$ mediums," Applied Surface Science, vol. 195, pp. 1-7, 2002.

[59] B. Ateya, B. E. El-Anadouli, and F. M. El-Nizamy, "The adsorption of thiourea on mild steel," Corrosion Science, vol. 24, pp. 509-515, 1984.

[60] E. E. Oguzie, V. O. Njoku, C. K. Enenebeaku, C. O. Akalezi, and C. Obi, "Effect of hexamethylpararosaniline chloride (crystal violet) on mild steel corrosion in acidic media," Corrosion Science, vol. 50, no. 12, pp. 3480-3486, 2008.

[61] M. Hosseini, S. F. L. Mertens, and M. R. Arshadi, "Synergism and antagonism in mild steel corrosion inhibition by sodium dodecylbenzenesulphonate and hexamethylenetetramine," Corrosion Science, vol. 45, no. 7, pp. 1473-1489.

[62] A. K. Singh and M. A. Quraishi, "Effect of Cefazolin on the corrosion of mild steel in $\mathrm{HCl}$ solution," Corrosion Science, vol. 52, pp. 152-160, 2010.

[63] W. Durnie, R. De Marco, A. Jefferson, and B. Kinsella, "Development of a structure-activity relationship for oil field corrosion inhibitors," Journal of the Electrochemical Society, vol. 146, no. 5, pp. 1751-1756, 1999.

[64] S. Martinez and I. Stern, "Thermodynamic characterization of metal dissolution and inhibitor adsorption processes in the low carbon steel/mimosa tannin/sulfuric acid system," Applied Surface Science, vol. 199, pp. 83-89, 2002.

[65] J. O. M. Bockris, M. A. Devanathan, and K. Muller, "Thermodynamic characterization of metal dissolution and inhibitor adsorption processes in the low carbon steel/mimosa tannin/sulfuric acid system," Proceedings of the Royal Society A, vol. 274, pp. 55-79, 1963. 
[66] M. A. V. Devanathan and Z. Stachurski, "The mechanism of hydrogen evolution on iron in acid solutions by determination of permeation rates," Journal of The Electrochemical Society, vol. 111, p. 619, 1964.

[67] E. J. Kelly, "Iron dissolution and hydrogen evolution reactions in acidic sulfate solutions," Journal of The Electrochemical Society, vol. 112, pp. 124-131, 1965.

[68] A. Frignani, M. Tassinari, and G. Trabanelli, "Impedance measurements on Armco iron in acid solution inhibited by Scontaining additives," Electrochimica Acta, vol. 34, no. 8, pp. 1259-1263, 1989.

[69] E. McCafferty and N. Hackerman, "Kinetics of iron corrosion in concentrated acidic chloride solutions," Journal of The Electrochemical Society, vol. 119, pp. 999-1009, 1972.

[70] H. Ashassi-Sorkhabi and S. A. Nabavi-Amri, "Corrosion inhibition of carbon steel in petroleum/water mixtures by $\mathrm{N}$ containing compounds," Acta Chimica Slovenica, vol. 47, no. 4, pp. 507-517, 2000.

[71] P. C. Okafor, M. E. Ikpi, I. E. Uwah, E. E. Ebenso, U. J. Ekpe, and S. A. Umoren, "Inhibitory action of Phyllanthus amarus extracts on the corrosion of mild steel in acidic media," Corrosion Science, vol. 50, no. 8, pp. 2310-2317, 2008.

[72] I. B. Obot and N. O. Obi-Egbedi, "Adsorption properties and inhibition of mild steel corrosion in sulphuric acid solution by ketoconazole: experimental and theoretical investigation," Corrosion Science, vol. 52, no. 1, pp. 198-204, 2010.

[73] D. W. Shoesmith, Metals Handbook, vol. 13, 9th edition, 1987.

[74] A. Fragnani and G. Trabanelli, "Influence of organic additives on the corrosion of iron-based amorphous alloys in dilute sulfuric acid solution," Corrosion, vol. 55, pp. 653-660, 1999.

[75] A. Popova, E. Sokolova, S. Raicheva, and M. Christov, "AC and DC study of the temperature effect on mild steel corrosion in acid media in the presence of benzimidazole derivatives," Corrosion Science, vol. 45, no. 1, pp. 33-58, 2003.

[76] N. Hackerman, E. S. Snavely Jr., and J. S. Payne Jr., "Effects of anions on corrosion inhibition by organic compounds," Journal of The Electrochemical Society, vol. 113, pp. 677-981, 1966.

[77] X. Li, S. Deng, H. Fu, and G. Mu, "Inhibition effect of 6benzylaminopurine on the corrosion of cold rolled steel in $\mathrm{H}_{2} \mathrm{SO}_{4}$ solution," Corrosion Science, vol. 51, no. 3, pp. 620-634, 2009.

[78] A. K. Satpati and P. V. Ravindran, "Electrochemical study of the inhibition of corrosion of stainless steel by 1,2,3benzotriazole in acidic media," Materials Chemistry and Physics, vol. 109, pp. 352-359, 2008. 

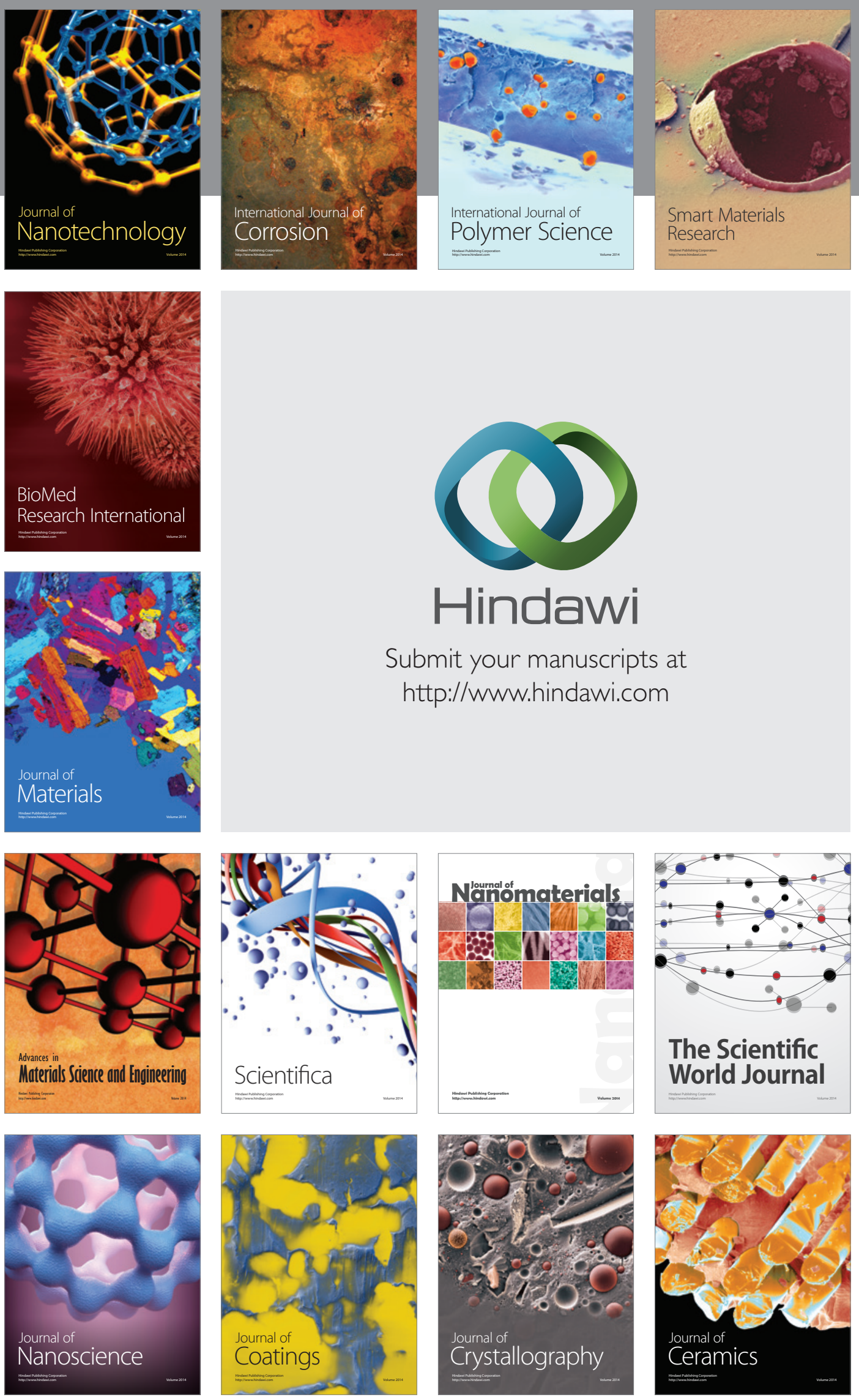

The Scientific World Journal

Submit your manuscripts at

http://www.hindawi.com

\section{World Journal}

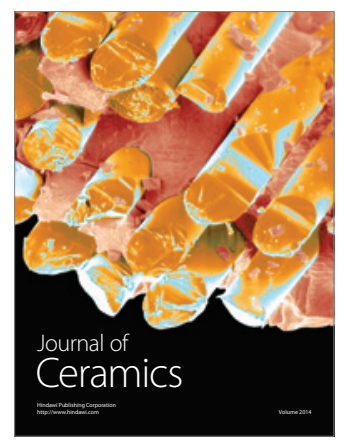

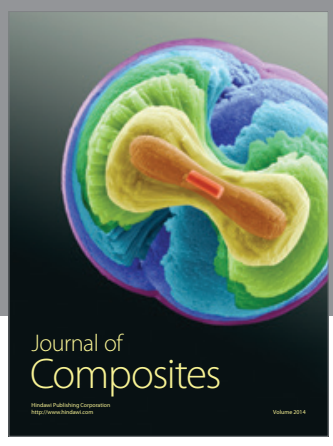
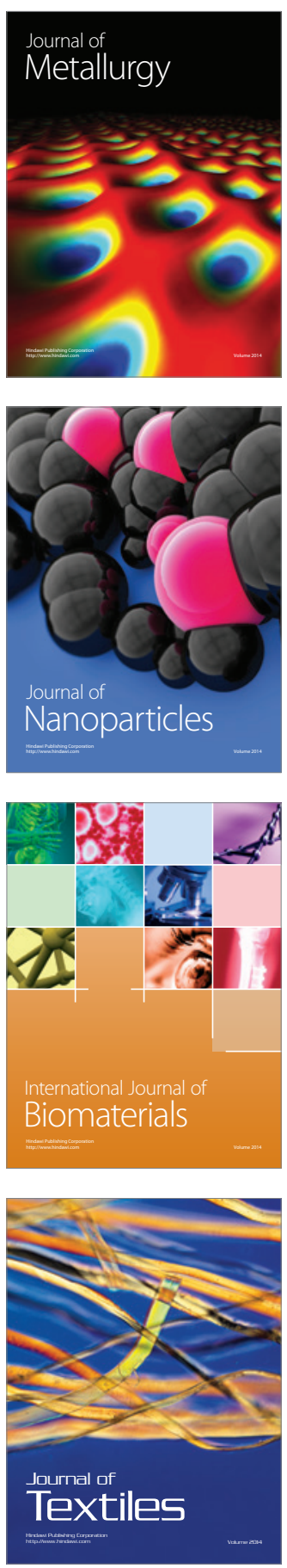